Revista Iberoamericana. Vol. LXIV, Núms. 182-183, Enero-Junio 1998; 241-252

\title{
LOS CULTOS MARIANOS NACIONALES EN AMÉRICA LATINA: GUADALUPE/TONANTZIN Y APARECIDA/IEMANJÁ
}

\author{
POR \\ Malgorzata Oleszkiewicz \\ The University of Texas at San Antonio
}

\author{
La estrella brilló \\ Allá en lo alto del Mar \\ Quien viene a salvarnos \\ Es nuestra Madre Iemanjá \\ Sé bienvenida \\ Nuestra Madre de mucho amor \\ Ven a salvarnos \\ Por la cruz del Señor. ${ }^{1}$ \\ Señora de Guadalupe \\ O Virgen de la Concepción \\ Negrita de mi Brasil \\ Madre Santa de liberación. ${ }^{2}$
}

No podemos hablar del nacimiento de una nueva naturaleza latinoamericana, criolla, mestiza o mulata, sin examinar la fusión de arquetipos a nivel mitológico y religioso que lleva a la creación de nuevos símbolos nacionales, diferentes de los de los países colonizadores y de los pueblos colonizados. Uno de estos símbolos religiosos y nacionales es la Virgen de Guadalupe, sincretizada con la diosa Tonantzin, en México y la Virgen Aparecida, una de las manifestaciones de la Virgen de la Inmaculada Concepción, identificada con la diosa yoruba Iemanjá, en el Brasil. Hay que aclarar que éstos son sólo dos ejemplos de la innumerable gama de fenómenos sincréticos y sus variantes que a nivel religioso existen en América Latina. En el caso de la Virgen de Guadalupe, ésta se ha vuelto un culto nacional e incluso continental, basado en su sincretismo con una gama de diosas aztecas de diferentes nombres y atributos

\footnotetext{
${ }^{1}$ Texto de un manual de devoción a Iemanjá citado en Iwashita (100). Traducción mía.

${ }^{2}$ La última estrofa del canto "É Maria, é Maria" de Zé Vicente, un conocido músico de las Comunidades Eclesiásticas de Base brasileñas, mezcla la Virgen de Guadalupe mexicana con la Virgen Aparecida brasileña, dos cultos nacionales. Citado en Boff (90, traducción mía).
} 
complementarios; y en el caso de Iemanjá, está a su vez identificada con diferentes vírgenes en diferentes localidades del Brasil y de Cuba, a la que se le da diversos nombres que designan sus variados aspectos. Aquí hay que remarcar que este sincretismo, facilitado por la veneración nacional de la Virgen negra Aparecida, fuerte y deliberado en el culto afro-brasileño Umbanda, hoy día se encuentra en un proceso de distanciamiento de los elementos católicos, en el Candomblé. Esto está ocurriendo desde los años ochenta, cuando acaban las persecuciones oficiales del culto. ${ }^{3}$ Sin embargo, la ligazón con el catolicismo permanece en el uso de símbolos, oraciones y misas en muchos terreiros (comunidades de culto).

Los cultos de la Virgen de Guadalupe y de la Virgen Aparecida/Concepción y Concepción/Iemanjá, son a la vez paralelos y contrastantes. La primera diferencia que percibimos es el hecho que, en el caso de México, la fuerza dominante parece ser la Virgen cristiana que bajo su nombre absorbe una gama de divinidades indígenas, mientras que en el caso de la diosa yoruba, Iemanjá, ella es la que incorpora diferentes vírgenes a la vez que a la Iara indígena y a la Sirena europea. En los dos casos, la divinidad llegada más tarde absorbe las anteriores e impone su nombre a las ya existentes. Así la Guadalupe española se sobrepone a la Tonantzin-Coatlicue azteca, y la Iemanjá africana a la Iara indígena, y a la Virgen de la Inmaculada Concepción y la Sirena europea (en el caso de Bahía). Sin embargo, Iemanjá, como divinidad africana, no se ha vuelto un culto oficial en el Brasil, aunque sí el culto más popular, especialmente en el nordeste del país. ${ }^{4}$ El culto nacional oficial del Brasil ha sido establecido para otra divinidad negra: la Virgen Aparecida, una estatua de la Virgen de la Inmaculada Concepción encontrada en las aguas del río Paraíba en el año 1717. Este culto es más fuerte en la parte centro-sur del Brasil, en los estados de Sao Paulo, Río de Janeiro y Minas Gerais.

La Virgen de Guadalupe fue traída a México por los conquistadores españoles, quienes como Hernán Cortés provenían en su mayoría de Extremadura, lugar del famoso santuario de la Virgen de Guadalupe de Villuercas. Sin embargo, ¿es esta Virgen extremeña la misma que con tanta devoción veneran hoy día los mexicanos? La respuesta es definitivamente "no". El culto de Nuestra Señora de Guadalupe de los Villuercas tuvo su apogeo a finales de la Reconquista y durante la Conquista de América (finales del siglo XV y comienzos del XVI). La milagrosa estatua de esta Virgen negra, sentada sobre su trono con el niño en las rodillas, fue encontrada por un pastor extremeño en el año 1322 y el monasterio de Villuercas se construyó en 1340 (Lafaye 295). Una reproducción de esta misma estatua fue probablemente la primera imagen de Guadalupe establecida en México. Sin embargo, este culto de los gachupines no duró mucho tiempo. Después de todo, era una imagen transplantada,

\footnotetext{
${ }^{3}$ Posición asumida en la Segunda Conferência Mundial da Tradição dos Orixás e Cultura, Salvador da Bahía, 17 a 23 de julio de 1983 (Boff 52 y 56).

4 El Brasil tiene el mayor número de población de origen africano en el mundo, después de Nigeria (Walker, "Candomblé ..." 12).
} 
y la híbrida realidad de la Nueva España necesitaba una imagen diferente, un símbolo que la uniera, que representara todas sus razas y creencias. En este contexto, surge la primera aparición de la Virgen de Guadalupe mexicana, impresa en la tilma del indio Juan Diego en 1531. Le siguen otras apariciones sucesivas y en 1609 se construye el primer santuario de la Virgen de Guadalupe en el cerro de Tepeyac. En 1629 y 1737 hay grandes inundaciones y epidemias, durante las cuales se multiplican las curas milagrosas, y se le atribuye a la Virgen la salvación de toda la comunidad. En 1737 Guadalupe recibe el título oficial de "Patrona principal de la ciudad de México" y ya en 1754 su tutelaje se extiende sobre toda la Nueva España (Lafaye 295).

Examinemos ahora la procedencia y características de esta "nueva" Virgen, patrona de México. La Virgen de Guadalupe se le aparece a un indio recién converso en el cerro de Tepeyac, conocido lugar de culto de la diosa indígena Tonantzin. La diosa Tonantzin, cuyo nombre significa "nuestra verdadera madre", diosa de la tierra y de la luna, aparece también bajo el nombre de Teteoinnam, "la madre de los dioses" y Toci, "nuestra abuela". Otros nombres con que se designan aspectos complementarios de la misma diosa madre terrestre son Coatlicue, "aquélla que tiene una falda de serpientes", madre del dios guerrero Huitzilopochtli, y Ciuacoatl, "mujer serpiente", madre del dios Mixocoatl. Otras diosas, como la Tonacaciuatl- "la señora de nuestra nutrición", Citlalicue - "aquélla que tiene una falda de estrellas" y Omeciuatl"Señora de la dualidad", están relacionadas con la nutrición. Estas y otras diosas representan en realidad diferentes aspectos de la misma deidad femenina, ligada a la tierra, a la maternidad y a la alimentación. Estas diosas terrestres tienen sin embargo también un aspecto guerrero, yaociuatl, y un aspecto terrible. Dan vida y "devoran" a sus propios hijos, completando así el ciclo vital. Este eterno retorno está simbolizado por la luna, uno de los atributos de estas diosas. Un buen ejemplo de una diosa que incluye todos estos aspectos es Tlazolteotl, "diosa de la inmundicia", diosa madre terrestre y lunar, del amor carnal y de la confesión, de la vegetación y de la fertilidad, que también rige la medicina mágica. Se la representa con un ornamento de la nariz en forma de media luna, el yacumetztli, que recuerda la unión mítica de la tierra con la luna y la influencia de ésta sobre la vegetación y la fertilidad (Soustelle 44-45).

En este breve recuento podemos observar que los aztecas, que también absorbieron las divinidades de otros pueblos indígenas, veneraban una divinidad femenina que incluía los diferentes aspectos de la vida y de la muerte, comprendidos como parte de un mismo ciclo. Además de la maternidad, estas diosas incluían también la sexualidad y la muerte, asemejándose así a las diosas de la antigüedad pagana, como Astarte-Istar o Hécate, que además de representar el aspecto de la Madre buena, tenían también el de la Madre terrible. Este arquetipo de la Gran Diosa cósmica representa en diferentes culturas el principio femenino, la energía creativa asociada fundamentalmente con la maternidad, el amor, la sexualidad, la muerte y la guerra. Personifica la tierra que puede engendrar y el agua que fertiliza (Iwashita 267). Otro ejemplo de este poder dual que a la vez mata y cura es la diosa hindú Kali, que da a luz a todos los seres del universo, pero al mismo tiempo su lengua larga y roja está lista para chupar su sangre. Kali, 
semejante a Coatlicue, lleva un collar de calaveras, y su falda está hecha de brazos y piernas cortadas (Campbell 25).

Otra expresión de la Gran Diosa y de la Gran madre cósmica es un niño sagrado, cuyo ejemplo es el hijo de Isis, Horus. Este hijo puede volverse esposo y hermano. El aspecto ambivalente del arquetipo de la Gran madre se manifiesta aquí en el hecho que el niño es casi siempre abandonado, pero es salvado y alimentado por otra persona. El aspecto mortal es entonces seguido por el renacimiento, tema que observamos en el ciclo de la naturaleza (Iwashita 268). Aquí también está el origen de la imagen de la Madona con el niño, representada antiguamente como una Madona negra sentada en su trono con el niño divino en las rodillas, igual que Isis con Horus.

En cuanto al tema de la Inmaculada Concepción y del nacimiento virgen, éste simboliza la transformación espiritual, el nacimiento del hombre y la mujer espiritual (The Power of Myth). Este aspecto aparece también en el caso de Coatlicue que "barriendo se encontró un haz de plumas, que colocó en su seno quedando encinta" (Soustelle 33). De esta "Inmaculada Concepción" nace el niño milagroso, el dios Huitzilopochtli. La paradoja de la madre virgen está repetida en Artemis de la Arcadia griega. Ella es la virgen cazadora, que a la vez preserva y destruye. La Artemis-Diana es representada en Efeso, Asia Menor, como la diosa de la fertilidad (Begg 50). Su imagen contiene senos, animales, vegetales y brazos extendidos, simbolizando así a la madre de todos los seres, la naturaleza. En algunas imágenes también aparecen las estrellas y la luna creciente, ya que Diana es también diosa de la luna y del cielo con su poder extendido sobre el mar. Igual que el arquetipo de la Gran madre, Diana es diosa de la vida y de la muerte (Iwashita 271-273). También en Efeso, lugar del templo de Artemis más importante, en el año 431 d.c. la Virgen María fue proclamada Theotocos o Madre de Dios (Begg 53).

Podemos observar que el arquetipo de la Gran madre, con su aspecto dual de proveedora de la vida y de la muerte, existe en las diosas precristianas europeas, en las diosas orientales, en las diosas indígenas mexicanas y también en las africanas. Un ejemplo es la diosa yoruba, Iemanjá, patrona de las aguas, madre de los dioses y de los hombres, que como la Sirena destruye a los que se le acercan. ¿Qué pasó entonces con María, heredera de Isis y de Artemis, que ha sido despojada de su aspecto de Madre terrible de su proximidad con la muerte, así como de su sexualidad? De hecho, de todos los atributos de las diosas, su virginidad es lo que se ha enfatizado más. Se la llama "Virgen" y no "Madre". Sin embargo, los católicos todavía veneran a María bajo nombres antiguos como "Madre de Dios", "Reina de los cielos", o "Santa Virgen". Otros nombres que también se le aplicaban antiguamente eran "Emperadora del infierno" y "Señora de todo el mundo". Como María llevaba muchos de los atributos de la Gran Diosa, a su culto se oponían los padres de la Iglesia cristiana. Hasta el siglo quinto la divinidad de María era negada y los marianitas, secta que la profesaba, eran perseguidos como heréticos. La Virgen María, como la conocemos hoy, encarna sólo uno de los aspectos de un concepto más antiguo de la Santa Trinidad que rige los ciclos de la creación, el nacimiento y la muerte en sus formas de Virgen, Madre y Bruja. Estos 
aspectos de María están presentes en las tres Marías que presencian la crucifixión de Cristo (B. Walker, viii y 602-609). Estos mismos aspectos están encarnados en la tríada de las diosas yoruba-brasileñas Oxum - la joven, Iemanjá — la mujer madura y Nana - la vieja, así como en las diosas mexicanas Xochiquetzal- la diosa de la primavera e hija de Coatlicue-Tonantzin - la diosa madre, y Toci-Teteoinnam"nuestra abuela". La cualidad guerrera, en el caso del panteón afro-brasileño del Candomblé, está encarnada por Iansa, orixá (diosa) de la guerra, de los vientos y las tempestades que enfrenta la muerte y acompaña a los espíritus en esta travesía(Siqueira 443), así como por uno de los aspectos de la diosa Oxum.

Otro aspecto que une a María, con las diosas de la antigüedad y las diosas indígenas y africanas es que estas diosas son a la vez madres y esposas de los dioses. En el caso de Iemanjá, de acuerdo a un mito, ésta se casa con su hermano Aganju y es violada por su hijo Orungan. De su vientre brotan los orixás (dioses). Ella es también reconocida como la esposa de Oxalá, orixá identificado con Jesucristo y la madre de casi todos los orixás. En México, la virgen lunar y diosa de los placeres del amor, la danza y el arte, Xochiquetzal, es también la madre y la amante de Xochipilli-Cinteotl, un joven dios del maíz. La identidad de esta diosa-virgen con la Gran madre primordial, señala también a ésta como virgen (Neumann 196-197). En cuanto a María, en el siglo III, Efraín de Siria la llamó Esposa de Jesús, a la vez que su Madre. En la Edad Media las catedrales góticas eran dedicadas a Nuestra Señora, la Notre Dame y no a la "Virgen". Muchas de ellas fueron construidas sobre templos paganos dedicados a la Gran Diosa. La Iglesia, Ecclesia, era uno de los títulos de María y era identificada con los edificios y con la organización de la Santa Madre Iglesia como Esposa y Madre de Dios (B. Walker 604-610). Sin embargo, el culto de María no fue adaptado fácilmente por la cristiandad por temor que este arquetipo de la Madre pudiera llevar de vuelta al culto de la Diosa. Recién en el siglo quinto se la llega a proclamar Theotokos o "Madre de Dios"; sin embargo María misma no puede aspirar a ser una diosa. Los variados aspectos cósmicos de la Diosa, relacionados con la materia y la sexualidad han sido disociados de la Virgen María, pasando a constituir el arquetipo de Eva, la mujer "mala" y "destructiva". Estos aspectos han sido demonizados y perseguidos desde la Edad Media mediante el fenómeno de la cacería de brujas.

En este contexto es importante examinar cómo los rasgos de esta mujer parcial encarnada en la Virgen María son complementados con otros, al entrar en contacto con diosas indígenas y africanas en América. La Virgen María, al sincretizarse con ellas, satisface la necesidad de los pueblos latinoamericanos de un culto y de una identidad nacionales. También les ayuda a identificarse con unas figuras femeninas más completas, madres, mujeres y amantes, que representan la totalidad de la vida y de la muerte, y por lo tanto simbolizan y ubican al ser humano en un universo ambiguo y dual, como el de la Colonia. Una figura como la Virgen María, despojada de diferentes aspectos de su femeinidad, no puede subsistir en su forma parcial en unas naciones que se preguntan por su propia identidad, que están en proceso de formación y encarnan el 
deseo de inclusión no sólo de ellas como grupos humanos, pero también de todos sus estratos raciales y étnicos. La aparición de la Virgen de Guadalupe en el cerro de Tepeyac lleva al sincretismo de ésta con la diosa Tonantzin, otorgando a los mexicanos la oportunidad de venerar a un arquetipo femenino más completo.

Al analizar la transformación de la imagen de la Virgen de Guadalupe, nos damos cuenta que la versión mexicana no se parece en nada a la original, encontrada en Villuercas y traida a la Nueva España como una imagen de bulto o estatua de la Virgen negra sentada, con su hijo en las rodillas. La nueva imagen mexicana de la Guadalupe tiene rostro indígena y representa a la Virgen sin niño, de pie, pareciéndose más a las imágenes de la Inmaculada, representada generalmente con su manto azul marino y un resplandor alrededor de la cabeza, parada sobre una media luna (Palmer 34). La imagen de Guadalupe, igual que la Virgen del Apocalipsis (Bayley 232), contiene los tres elementos esenciales para los aztecas: el sol, la luna y las estrellas. Su cuerpo está rodeado por un resplandor solar, su manto es estrellado y bajo sus pies se encuentra una media luna (Cuadriello 17-23). En el caso de Guadalupe, el azul marino del manto de la Inmaculada se transforma en turquesa o jade, el color sagrado de los aztecas. Según la simbología náhuatl el verde-azul, que en esta lengua está designado por una sola palabra, simboliza agua y fuego, prosperidad y abundancia vegetal y es atributo de Tlazolteot l o "diosa de la inmundicia" y diosa madre terrestre y lunar, y de Chalchiutlicue, diosa del agua y de la fecundidad, "la que tiene una falda de piedras verdes". El azul es también el color del sur y del dios guerrero Huitzilopochtli, hijo de Coatlicue. La túnica de Guadalupe es rojiza y el color rojo está asociado entre los aztecas con el este, la salida del sol y el renacimiento vegetal, con la juventud y el placer (Soustelle 80-82). Otra "coincidencia" es que esta imagen también se asemeja a la de la Virgen del Apocalipsis, que bajo sus pies apoyados en la media luna tiene al dragón vencido (Palmer 93), el dragón-materia/sexo que desde la Edad Media es demonizado en Europa y que Coatlicue, en su aspecto dual, incorpora.

¿Y cómo es que Iemanjá, la diosa madre yoruba, está relacionada con su contraparte cristiana, la Virgen María? Hemos dicho que Iemanjá es parte de la trinidad femenina Oxum-Iemanjá-Nana. ${ }^{5}$ También forma parte del grupo de la iabás u orixás femeninos, relacionados con las aguas, con atributos maternales o conyudales, entre los cuales también están Iansa y Oba. Iemanjá es la diosa de las aguas del mar y la madre de los dioses y de todos los seres. Su nombre significa "madre cuyos hijos son peces". Es a la vez la Madre buena que da vida y la Madre terrible cuya furia provoca la muerte de los pescadores. Cuando mueren, ella es también su consorte en el fondo del mar. Los marinos son seducidos por ella, como por las Sirenas. Igual que en el caso de la Virgen María, sus colores, son el blanco y el azul y su día es el sábado. A Iemanjá se le atribuyen muchos nombres, de acuerdo a sus diferentes aspectos: "Sirena", "Madre del agua", "Dueña del mar", "Iemanjá", "Janaína", "Señora María", "Inaê", "Princesa

\footnotetext{
${ }^{5}$ Oxum-diosajoven de agua dulce; Iemanjá-diosa madre de las aguas del mar; y Nana-diosa vieja de agua dulce con la cual transforma la tierra en lodo, relacionada con la muerte.
} 
de Aiocá" (Amado 81) "Iara" " “Calunga”. Es significativo que, gracias a la influencia de Iemanjá, María recobra su título de "Señora". Como "Madre del agua", Iemanjá da vida y alimento y como "Calunga" trae la muerte. Además de diosa, Iemanjá es una presencia palpable, una madre, una amante, una mujer. Es la madre de familia y la señora de la casa, sexualmente potente. Es el símbolo de la mítica mujer brasileña (Siqueira 441). Se la representa como una mujer fecunda con senos grandes y caderas anchas, como a las diosas de la antigüedad. Curiosamente, en sus imágenes brasileñas más difundidas que vienen del culto de la Umbanda, su piel es blanca y su pelo negro y largo. En ese aspecto podríamos decir que es una versión más terrestre de las imágenes tradicionales de la Inmaculada, ya que lo que se acentúa aquí es precisamente su potencia sexual y reproductiva. Sus atributos son también el sol, la luna y la estrella, porque de acuerdo con un testimonio recogido por Lydia Cabrera en Cuba, "la reina de los mares es la santa de mayor querarquía, le pertenecen el sol, la luna y la estrella ... Su corona [es] el Arco Iris, Ochumaré ... Los [indios] arará dicen que es una serpiente, y la llaman Jaído" (Cabrera 268). En una reciente fiesta en el terreiro bahiano de Gantois, hemos observado que el traje de Iemanjá tenía el motivo de un cielo estrellado, iluminado por la luna. ${ }^{6}$

Parte de una trinidad similar de virgen, madre y bruja, como Iemanjá, es la diosa griega Afrodita. Aparece bajo el nombre Venus o "Reina de los mares", llamada también Mari o Maria en latín, lo cual significa "Los mares". Mari, como Iemanjá, lleva una túnica azul, simbolizando el color del mar. Esta diosa es identificada con la Virgen María. Es también un pescado grande que da a luz a los dioses, más tarde convertida en Sirena o Mareminde. Iemanjá, sincretizada con la Virgen María, nos lleva a su atributo primordial de Madre de los mares. Sin embargo, Mari-María, igual que Iemanjá, es también la tierra y el cielo, ya que su forma originaria es la de una trinidad (Walker 44, 584).

¿Qué tienen en común las figuras de Guadalupe, y Aparecida/Iemanjá y por qué se han vuelto símbolos de la nacionalidad de México y del Brasil respectivamente? Para responder a esta pregunta es preciso examinar la historia y las necesidades de las nuevas repúblicas latinoamericanas, como las de otros pueblos amenazados por el poder exterior, que están interesados en construir y preservar su identidad nacional.

Es notable que tanto Guadalupe como Aparecida y Iemanjá recogen elementos heterogéneos, étnicos, raciales y culturales, de los pueblos en que surgen. En México estos elementos son predominantemente españoles e indígenas, y en el Brasil africanos, portugueses y en menor grado indígenas, representando así a los principales estratos de la población. En ambos países, las figuras de Guadalupe, Aparecida y Iemanjá inspiran respeto, homenajes, leyendas, cantos, narrativas, nombres y estudios. En México se habla del guadalupanismo y en el Brasil del iemanjismo, como un culto aparte. ¿Por qué estas figuras se han vuelto tan veneradas en estos dos países,

\footnotetext{
${ }^{6}$ Nos referimos a la fiesta consagrada a Nana, identificada con la señora Santa Ana, realizada en el terreiro de Gantois el 28 de julio de 1996.
} 
adquiriendo la importancia de cultos nacionales? Tanto Guadalupe en México como Aparecida y Iemanjá, que comparten el culto nacional, oficial o no, en el Brasil, están basadas en el arquetipo de la Gran Diosa que abarca tanto los aspectos positivos como los negativos del universo. Representan a la naturaleza y a la madre, de la cual tanta necesidad tienen estas nuevas naciones, con poblaciones arrancadas de su antigua tierra, cultos o costumbres. A la vez, como naciones heterogéneas, nuevas y amenazadas por posibles agresiones, están necesitadas de símbolos nacionales que las aglutinen. En el caso de México, tenemos las luchas por la Independencia y la resistencia contra la constante amenaza de las potencias extranjeras. Este aspecto de resistencia se vería confirmado por otro caso de un culto nacional famoso, el de la Madona negra de Czestochowa, llamada "Reina de Polonia," que desde los principios de la consolidación del catolicismo en este país y durante siglos de invasiones, repartimientos y amenazas extranjeras, hasta hoy día sirve para dar ánimo a los polacos y para consolidar su sentido de nacionalidad. Así Matka Boska Czestochowska, la patrona de Polonia, tiene su contraparte en la Virgen de Guadalupe, patrona de México y en la Virgen Aparecida, patrona del Brasil, opacada por Iemanjá en el nordeste.

Aunque Iemanjá no ha sido oficialmente proclamada patrona del Brasil, y sería difícil que lo fuera, considerando su procedencia y nombre africanos, de hecho se ha vuelto la figura más venerada en este país, especialmente en la región del nordeste, junto con Aparecida, a quien se venera principalmente en el centro-sur. La que tomó la batuta oficial es la Virgen Aparecida, cuya historia tiene muchas similitudes con la de la Virgen de Guadalupe. La Virgen Aparecida fue una estatua de la Virgen de la Inmaculada Concepción negra, de 36 centímetros de altura, encontrada "milagrosamente" por unos pobres pescadores en las aguas del río Paraíba en el año 1717. Su aparición fue seguida por una serie de milagros, incluyendo el rompimiento por sí solas de las cadenas de un negro esclavo. En 1745 se construyó una capilla en su honor, en 1888 una iglesia y en 1955 se comenzó la construcción de la enorme Basílica Nueva, inaugurada en 1980. En 1930, Aparecida fue declarada por el papa Pío XI patrona del Brasil y en 1931 se realizó la consagración de la nación a esta Virgen negra, declarándola "Reina del Brasil". Su santuario adquirió una proyección nacional. Los comienzos del culto de esta Virgen negra señalan también la aparición histórica del

\footnotetext{
${ }^{7}$ En el año 1980, el papa Juan Pablo II, durante la consagración de la Basílica Nueva, dedicada a la Virgen Aparecida, dijo:

Senhora Aparecida, um filho vosso

que vos pertenece sem reserva-totus tuus!-

um filho vosso chamado por misterioso

Desígnio da Providência

a ser Vigário de vosso Filho na terra,

quer dirigir-se a vós, neste momento.

Ele lembra com emoçao, pela cor morena

dessa vossa imagem, uma outra

representaçao vossa,

a Virgem Negra de Jasna Góra! (Lima 36).
} 
pueblo brasileño como pueblo autónomo. La guerra de los emboabas (forasteros) en 1708-1709 representa los primeros brotes del nacionalismo brasileño (Boff 19-29, 39).

Iemanjá es celebrada en cultos brasileños que abarcan todas las regiones y estratos de la población, tales como el Candomblé, la Umbanda y la Quimbanda y en grandes ceremonias públicas, como las de las playas cariocas y fluminenses, que adquieren dimensiones nacionales. Los cultos de Iemanjá y el de Aparecida se han desarrollado más tarde que el de Guadalupe. Esto se debe a las diferencias en el proceso sociohistórico del Brasil en comparación con el de México. En contraste con Tonantzin, Iemanjá fue traída al Brasil por los grupos africanos, consolidándose con la llegada de los nagô, a finales del siglo XVIII y principios del XIX. Fue retomada y constituida en una divinidad de aspecto diferente, que incluye características indígenas y europeas, en la Umbanda. Hasta los años ochenta del siglo XX, las ceremonias de los cultos afro-brasileños eran perseguidas y tenían que realizarse en secreto. Este hecho favorecía el sincretismo. A las deidades africanas se les daba identidades de santos cristianos. Sin embargo, como hemos mencionado, desde que se suspendieron las persecuciones, hay un proceso inverso, el de una africanización conciente en el culto yoruba-católico, Candomblé, mientras que la Umbanda, un culto con influencias más diversas: africanas, católicas, indígenas, kardecistas, orientales, esotéricas y hasta masónicas, asume una actitud sincrética deliberada. Al mismo tiempo, el culto del Candomblé, de la Umbanda y de Iemanjá actualmente se encuentran en un proceso de expansión en el Brasil.

Pero ¿cuál es la relación entre Aparecida y Iemanjá, ambos cultos de gran proyección? ¿Son dos figuras separadas o dos manifestaciones de la misma entidad? Hay que comenzar con el hecho de que las dos son mujeres con las cuales se identifica el pueblo brasileño, y sobre todo la mujer negra. Una canción popular del cantante afrobrasileño, Milton Nascimento, "Maria, Maria”, expresa así la solidaridad de María con el pueblo negro oprimido:

María, María, es el son, es el color, es el sudor

Es la dosis más fuerte y lenta

De una gente que ríe cuando debe llorar,

Y no vive, apenas aguanta (traducción mía).

Tanto Aparecida como Iemanjá, como madres, tienen una función protectora y como señoras - representan el poder. También ambas son figuras vitales y afectivas que están muy cerca de las personas. Esto es especialmente visible en la expresión popular brasileña Minha Nossa Senhora! (¡Mi Nuestra Señora!) (Boff 15). Como Virgen negra, Aparecida representa al oprimido pueblo brasileño. Según Frei Clodovis Boff, por causa de la identificación Aparecida-Brasil negro, fue favorecido el proceso del sincretismo de María con las diosas de las religiones afro-brasileñas, como Oxum o Iemanjá. También existe una identificación de la mae-de-santo (iyalorixá), sacerdotisa afro-brasileña, con la Gran Madre de Dios, por el color negro y una análoga función 
espiritual de tipo mediacional materno (Boff 44-45). Según Azevêdo (57), como muchas iyalorixás son vírgenes por causa de su sacerdocio, son también "madres vírgenes" con muchos hijos iniciados. Otra cosa que une a Aparecida y Iemanjá es que ambas son identificadas con Nuestra Señora de la Inmaculada Concepción. Curiosamente, en 1640 esta Virgen fue declarada patrona de todos los reinos de Portugal, inclusive del Brasil, cuya capital era entonces Salvador da Bahía. Ya desde antes, el catolicismo portugués era profundamente mariano. La Virgen de la Concepción era la patrona de los navegantes portugueses, y por eso, igual que la Iemanjá y la Aparecida brasileñas, estaba ligada a las aguas. Hoy día, Nossa Senhora da Concepçao da Praia es considerada por la Iglesia "la única patrona de Bahía" (padroeira única do estado da Bahía).

Es también muy importante el antes mencionado aspecto de resistencia, que a nivel interno está fuertemente ligado a la apropiación de María por el pueblo afrobrasileño. En un cántico de las Comunidades Eclesiásticas de Base, titulado "Mae negra Aparecida" (Madre negra Aparecida), se usan expresiones como Senhora negra, Yayá querida (Señora negra, niña querida), Soberana quilombana (Soberana de los quilombos), Olorum, nosso Deus (Olorum, nuestro dios), Menina Yaô (Niña Yaô). Estas expresiones presentan a María como una mujer negra iniciada en los misterios africanos (yấ) y soberana de los espacios de autoliberación de los esclavos fugitivos que eran los quilombos. También se le da el lugar máximo, correspondiente al dios supremo de la religión nagô, Olorum (Boff 87-88). Su extraordinario poder de diosa madre/padre está cargado de potencial de liberación:

\author{
Ven, María mujer, \\ A enseñarnos tu nuevo canto \\ Un Dios con rostro de madre \\ ¡Ven a los pobres anunciar! ("Vem, Maria Mulher”) \\ Mujeres en la historia oprimidas, \\ Tamaña discriminación \\ Levantan la voz y proclaman: \\ ¡Es hora de liberación! (“Eu te saúdo, Maria”, Boff 83, traducción mía).
}

Se ha escrito mucho sobre la orfandad de América Latina, continente despojado durante la Conquista de sus reyes semi-divinos. México y Brasil, dos de los países más extensos y heterogéneos de Latinoamérica, y dos naciones huérfanas, con una enorme necesidad de figuras protectoras y aglutinantes, las encontraron en su veneración del arquetipo de la Madre, elevado a una dimensión divina. La búsqueda de protección y de fortalecimiento de una identidad nacional y de clase ha dado a luz el culto de la Virgen de Guadalupe mexicana y el de la Apareciday Iemanjá brasileñas. ${ }^{8}$ Estos cultos

\footnotetext{
${ }^{8}$ Como hemos discutido anteriormente, el culto del Candomblé ha llegado a tener una función inversa, la de la resistencia contra los blancos y la búsqueda de una identidad africana. Incluso
} 
son sincréticos y sus imágenes están basadas en la Virgen de la Inmaculada Concepción, celebrada el ocho de diciembre, así como en las diosas indígenas y africanas. ${ }^{9}$ Aunque fueron apropiados particularmente por los pobres de color, abarcan todas las razas y clases sociales, constituyendo quizás la única fuerza que, fuera del hecho de vivir en el mismo suelo, es capaz de traspasar las enormes diferencias raciales, étnicas y económicas de sus habitantes. Los cultos de la Virgen de Guadalupe, de la Virgen Aparecida y de Iemanjá son también los símbolos que mejor reflejan la diversidad de México y de Brasil, volviéndose así una importante fuerza de consolidación nacional.

\section{OBRAS CITADAS}

Amado, Jorge. Mar Morto. Río de Janeiro: José Olympio, 1936.

Azevêdo, Carlos Alberto. "Mitos e Ritos nos Grupos de Culto Afrobrasileiros". Tesis de bachillerato. Recife: Universidade Federal de Pernambuco, 1971.

Augras, Monique. "De Iyá Mi a Pomba Gira: Transformações e Símbolos da Libido". Escritos sobre a Religião dos Orixás de Carlos Eugênio Marcondes de Moura (org.). São Paulo: Edicon, 1989. 14-33.

Bayley, Harold. The Lost Language of Symbolism Vol. 1. 1912. Londres: Bracken Books, 1996.

Begg, Ean. The Cult of the Black Virgin. London: Arkana, 1985.

Boff, Frei Clodovis. Maria na Cultura Brasileira Aparecida, Iemanjá, Nossa Senhora da Liberação. Petrópolis: Vozes, 1995.

Cabrera, Lydia. Yemayá y Ochún. New York: Colección del Chicherukú en el exilio, 1980.

Campbell, Joseph. Occidental Mythology: The Masks of God. 1964. Nueva York: Penguin Books, 1987.

Cuadriello, Jaime. "Mirada apocalíptica visiones en Patmos Tenochtitlan la mujer águila”. Artes de México. Santa Ana, CA: Bowers Museum of Cultural Art 29 (s.f.): 10-23.

Lima, Antônio Lúcio da Silva, org. Rezando com Nossa Senhora Aparecida. São Paulo: Paulus, 1991.

\footnotetext{
así, en el Candomblé son aceptadas personas de todas las razas y clases sociales. En una sesión en el terreiro Casa Branca, dedicada al orixá Oxossi, que presenciamos en Salvador da Bahía el 6 de junio de 1996, las diferentes funciones rituales fueron desempeñadas por personas de todas las razas y condiciones sociales, desde blancos y rubios hasta puramente africanos, desde profesionales renombrados hasta personas de la más baja condición social. Sin embargo, hay que aclarar que el meollo del culto del Candomblé está constituido por mujeres negras mayores, que son las que tienen más importancia, tanto por sus funciones como por su número. Podemos decir que en el Candomblé predomina un sistema matriarcal.

${ }^{9}$ Es curioso que, hasta algunos años atrás, en Bahía ese mismo día se realizaba el festival de la sociedad secreta femenina Gèlèdè, con el objetivo de aplacar las Iyá Mi, las terribles madres ancestrales (Augras 15).
} 
Iwashita, Pedro. Maria e Iemanjá: Análise de un Sincretismo. Sao Paulo: Edições Paulinas, 1991.

Joseph Campbell and the Power of Myth. Video. Program Five "Love and the Goddess". Apostrophe Productions Inc., 1988.

Lafaye, Jacques. Quetzalcóatl and Guadalupe: The Formation of Mexican National Consciousness 1531-1813. Chicago \& Londres: The University of Chicago Press, 1976.

Neumann, Erich. The Great Mother. 1955. Princeton: Princeton University Press, 1991.

Palmer, Gabrielle y Donna Pierce. Cambios: The Spirit of Transformation in Spanish Colonial Art. Albuquerque: Santa Barbara Museum of Art in Cooperation with the University of New Mexico Press, 1992.

Siqueira, Maria de Lourdes. "Iyámi, Iyá Agbás Dinámica da Espiritualidade Feminina em Templos Afro-baianos”. Estudos Feministas 3 (1995): 436-445.

Soustelle, Jaques. Pensamiento cosmológico de los antiguos mexicanos. París: Librería Hermann y Cia. Editores, 1959.

Walker, Barbara G. The Woman's Encyclopedia of Myths and Secrets. 1983. San Francisco: Harper, 1986.

Walker, Sheila. "Candomblé: A Spiritual Microcosm of Africa". Black Art: An International Quarterly 5 (1984): 10-22.

Woortman, Klaas. A Família das Mulheres. Río de Janeiro: Tempo Brasileiro, 1987. 